\title{
The effect of circadian rhythms on shipping accidents
}

\author{
Juan Vinagre-Ríos, ${ }^{1}$ José-Manuel Pérez-Canosa, ${ }^{2 *}$ and Santiago Iglesias-Baniela ${ }^{1}$ \\ ${ }^{1} \mathrm{PhD}$ (Nautical Sciences). Ship's Captain. \\ ${ }^{2}$ Navigation Sciences and Marine Engineering Department, A Coruña University, A Coruna, Spain. \\ *Corresponding author. E-mail: jose.pcanosa@udc.es
}

Received: 18 June 2020; Accepted: 11 March 2021; First published online: 13 April 2021

Keywords: safety, human error, bridge

\begin{abstract}
It is a well-known fact that humans are subject to circadian alterations caused by the action of sunlight. This strongly affects their behaviour and skill, making them change their level of alertness from high at daytime to low at nighttime. Taking into account this biological feature, and considering that commercial shipping is one of the oldest round-the-clock activities, raises the question whether bridge watchkeepers can carry out their tasks on night shifts with the same level of alertness as on day shifts. Furthermore, night bridge watchkeeping has to be performed in darkness or very dim light to improve the visual capacity of lookouts. A sample of vessel collisions was analysed and it was find out that this kind of accident tends to be more frequent and more serious during the darkness period of the solar day.
\end{abstract}

\section{Introduction}

Investigations have shown that humans maintain a roughly $24 \mathrm{~h}$ cycle of physiological and behavioural changes following the daily light-dark cycles. Thus, most adults have a decrease in alertness during the night and a rise during the day. This tendency is disrupted when the natural sleep-wake cycle changes due to working at unusual times of the day. In round-the-clock activities, this biological characteristic of humans limits their capabilities. Under shift work schedules, people's performance can be hindered, particularly during night work. Many studies dealing with different industrial shift work situations have shown that there is a tendency for people to make more errors during night shifts than during day shifts. Some of these investigations even conclude that the risk of accidents is significantly higher during night shifts (Cappuccio et al., 2018. pp. 181-182).

Commercial shipping is performed in a very hostile environment on a round-the-clock basis. These special working conditions require the shift work organisation on board to be adequate to achieve an appropriate level of safety. Furthermore, to improve the visual capacity of lookouts, bridge navigation tasks during night-time have to be performed in very dim light. This labour peculiarity, added to the general inconvenience of shift work systems and unpleasant living conditions, makes people engaged in navigation tasks more prone to errors during night shifts (Russ, 2018).

The concern that shipping companies set unsafe bridge watchkeeping working conditions on their ships emerges from the widespread opinion that excessive working hours (Yilmaz et al., 2013) and fatigue (Lloyd's List, 2012) have become a current problem in vessel safety (Kelly and Adamopoulos, 2017). This work-related anomaly has been clearly shown in many accident investigations, in which fatal errors are detected to such an extent that the human element is recognised as one of the major contributors to shipping accidents (Dickie, 2014. p. 185). The current state of the shipping industry appears to be the result of a risk compensation process, in which, to improve the competitiveness of their vessels, shipping managers tend to exchange investment in technical advances for reductions in 
manning levels in accordance with cost reduction policies (Baniela and Ríos, 2010). This behaviour is explained by the psychological theory which establishes that the greater the benefits, the greater the amount of risk people are willing to take (Vinagre-Ríos and Iglesias-Baniela, 2013).

We should bear in mind that controversial though these policies may be, they comply with the legal framework, which calls into question the effectiveness of government regulations regarding minimum safe manning on vessels. Moreover, these practices suggest that legislation is very lax about improving the safety of navigation. This legal inadequacy is perceptible in many countries where working hours for sea transport are dealt with in an extremely unfavourable way when compared with other haulage industries (Anderson, 2013. pp. 183-188). In the European Union, for instance, the rules for road transport do not allow a driving time of more than $9 \mathrm{~h}$ a day (OJ L 102, 2006), while for sea transport, which takes place in a more hostile environment, the limit is extended to $14 \mathrm{~h}$ (OJ L 167, 1999).

The ineffectiveness of regulations and industrial practices in dealing with the psychophysical disorders of people on board becomes particularly noticeable on the bridge navigation shift-working at night. This is supported by research findings that the effect of circadian disorders on human alertness is more intense in the absence of light, the common situation on a ship's bridge during the night (Cajochen et al., 2000). The idea that darkness has a negative influence on the safety of navigation can be deduced, not only from the situation of the industry, but also from many disastrous accidents. In fact, the world's worst peacetime shipping accidents have happened during night-time.

Taking into consideration the circumstances mentioned above, the aim of the present paper is to investigate if the average level of alertness of people engaged in bridge navigation tasks on board the world's merchant fleet is lower at night. For this purpose, the study analysed, first, if shipping accidents are more frequent during night shifts than during daylight shifts and, second, if the response to incidents that occur at night is slower than during daylight shifts, which would make accidents more serious at night. Investigations in industries not related to maritime transport have concluded that accidents take place more often during night shifts. Nevertheless, the novelty of this paper is that it deals with the world's commercial fleet incidents.

\section{The influence of light on the level of alertness}

It is known that the human circadian rhythm is a process governed by a biological clock located in the brain called the suprachiasmatic nucleus (SCN). This internal clock consists of circadian genes and the proteins that they encode which constitute a timekeeping system. It adapts the organism to the changes in the physical environment associated with day and night, and also ensures that internal changes are happening in coordination with one another (Klein et al., 1990. pp. 13-16).

The SCN, as a master pacemaker, receives information continuously about the level of light through the eyes by retina photoreceptors of the vision and specialised ganglion cells. Thus, an internal timing mechanism that coordinates physiological and behavioural processes to maintain synchrony with the environment is activated. Depending on the luminous information detected, the SCN transmits neural impulses to the pineal gland where melatonin synthesis and secretion is stimulated. In this way, melatonin is secreted into the cerebrospinal fluid and also into the blood stream. In normal individuals, the quantity of melatonin in blood depends on the exposure to daylight. The levels of melatonin are high at night and are minimal during the daytime. This biological process gives rise to a rest-activity cycle in individuals (Arendt, 1995. pp. 84-88).

The level of pineal melatonin secretion is employed as a marker rhythm in many studies to evaluate the state of the circadian clock and the associated grade of alertness. Many investigations show that the lower the levels of melatonin, the faster the reaction times will be in tasks of sustained attention. This relationship is shown during a day cycle in Figure 1, where the left vertical axis indicates the average serum melatonin (MLT) concentration (picograms per millilitre) of all age groups subjects (Tozawa et al., 2003). The right vertical axis indicates the average variation of alertness of a group of bridge officers according to the time of day, measured in a modified Karolinska Sleepiness Scale (KSS) (Härmä et al., 2008). The horizontal axis indicates the clock time. 


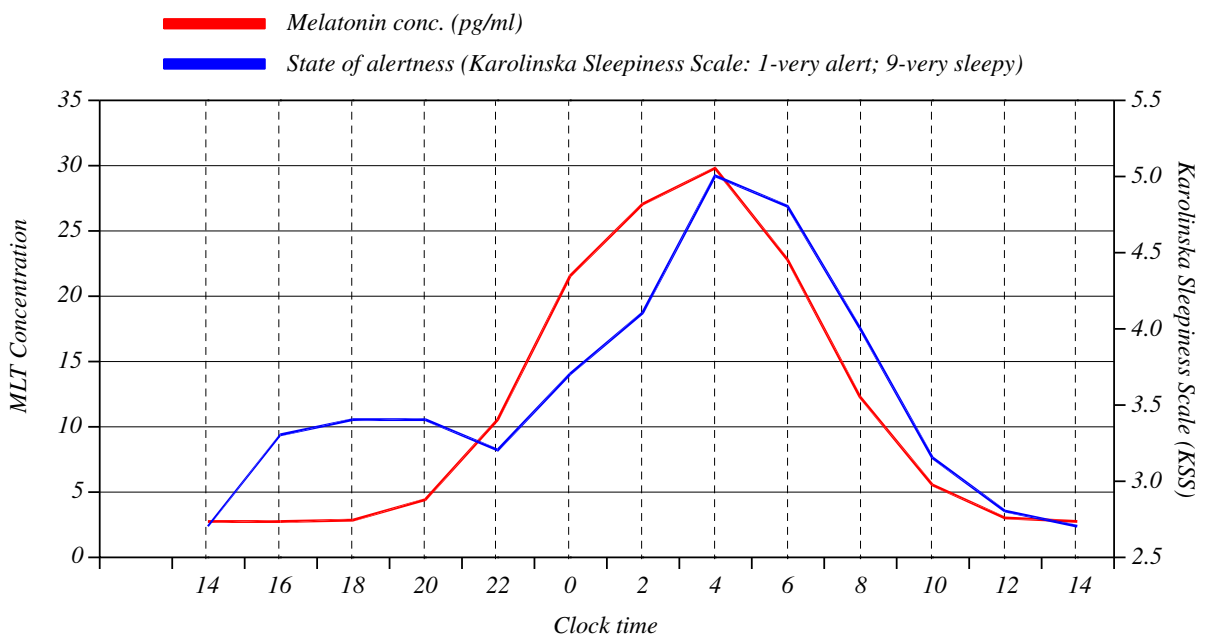

Figure 1. Raw data plots of average serum MLT secretion in all age groups subjects and level of alertness of a group of bridge watchkeepers according to the time of day.

It is accepted that light exposure not only entrains the circadian system in humans (Kumar, 2017), but also induces changes in their behaviour and enhances their level of alertness (Dawson and Campbell, 1991). This last effect is so important that many experiments have concluded that there is a close relationship between the grade of intensity of lighting and the level of alertness, in other words, the brighter the light, the greater the effect on subjective and objective measures of alertness (Cajochen et al., 2000).

Circadian cycles make the human disposition to work much lower in darkness conditions, therefore, it can be deduced that individuals forced to work at night without adaptation could be subjected to physical and psychical disturbances. In fact, it has been proved that establishing sleep-wake cycles out of synchronisation with the circadian rhythms leads to chronobiologic disorders, which alter human health (Rana and Mahmood, 2010) and imposes risks (Folkard et al., 2006). Some investigations show that shift workers tend to have more health problems and are more often associated with increased rates of work-related accidents than the general population (Iskra-Golec et al., 2016. p. 23).

Adaptation of the circadian phase to shift work schedules can be achieved by controlling the light/dark exposure. Thus, it is proved that people exposed to a light stimulus in the early night could have a phase delay shift and, conversely, light stimulus in the late night could produce a phase advance shift. These findings show how people can adapt to night shifts. Consequently, this helps to improve the performance of night workers who can, in this way, increase their brain activity, reduce sleepiness and improve mood (Horowitz et al., 2001). Moreover, it has been demonstrated that the use of high intensity lighting in workplaces during the night can help to increase the level of alertness of the persons engaged in night work and can also make them sleep better and longer during the day (Calhoun, 1999. p. 24).

The effect of light on human alertness and mental functioning is well documented in many studies. One such investigation dealt with the optimisation of the performance of shift workers and concluded that adaptation to night work is not effective in weak lighting. That experiment showed that high levels of sleepiness in night shift workers happen when low light conditions prevail in the workplace. On the contrary, a good adaptation was observed with decreased sleepiness of night shift workers when high intensity lighting was used in the workplace during the night (Postnova et al., 2013). When night shift workers subjected to sleep restrictions were required to perform their jobs in darkness or very dim light, both their subjective and objective levels of alertness decreased and their performance was worse, compared with working daylight shifts (Daurat et al., 1993).

Very dim light conditions at night are necessary for bridge lookouts to identify lights of other ships efficiently against the dark background of the sky and the sea. This poor lighting during the night 
reduces the level of alertness of people when they are subjected to sleep restrictions, a fact that makes ship bridges problematical workspaces (Wynn et al., 2012). Darkness appears to be a desirable condition in ship bridges to improve the visual capacity of watchkeepers but, at the same time, when they are sleep deprived it prevents them from effectively fulfilling their tasks. An example of the consequences of these working conditions on the behaviour of bridge officers is reflected in research carried out among Finnish bridge officers (see Figure 1), where it was found that sleepiness increased in the night shifts and decreased in the day shifts (Härmä et al., 2008).

\section{Sea watches on board and the circadian disorders}

Since commercial ships operate round-the-clock, shift work schedules are arranged to handle the hours of watch and rest of those on board. Compared with other industries, marine watchkeeping is influenced by many other factors, such as noise, motion, time zone crossings in navigations associated with rapid changes in longitude, and alterations in daylight length in navigations with significant changes in latitude. These peculiarities, which are inherent to maritime transport, disrupt the operational efficiency of watchkeepers (Condon et al., 1988).

Even though there are diverse watchkeeping systems in non-commercial ships, in merchant vessels worldwide, navigation bridge watchkeeping is usually scheduled in six periods of four consecutive hours. In this work plan, officers and lookouts shift in a fixed four-on/eight-off system. Thus, from 00.00 to $04.00 \mathrm{~h}$ (middle watch) and from 12.00 to $16.00 \mathrm{~h}$ (afternoon watch) one mate is on duty; from 04.00 to $08.00 \mathrm{~h}$ (morning watch) and from 16.00 to $20.00 \mathrm{~h}$ (dog watch) another mate is on duty; and from 08.00 to $12.00 \mathrm{~h}$ (forenoon watch) and from 20.00 to $24.00 \mathrm{~h}$ (first watch) a third mate is on charge of the watch.

Ships engaged in coastal navigation or short voyages usually arrange a six-on/six-off watch system. As this schedule allows ship-owners to reduce manning costs, many shipping companies that had been operating their vessels in a 4/8 schedule have changed to this $6 / 6$ system. Comparing both watchkeeping schedules, the six-on/six-off watch system implies shorter sleeping times and more working hours for watchkeepers and lookouts compared with the four-on/eight-off system. For this reason, the 6/6 system can be considered a more disruptive schedule. It is a widespread opinion that a perceptible reduction in cognitive effectiveness affects crews operating in $6 / 6$ shifts, compared with other work shifts with fewer working hours (Paul et al., 2010). Studies reflect that six-on/six-off sea-watch schedules produce high levels of sleepiness in watchkeepers during the night and early morning watches because of the shortage of sleep duration caused simply by the circadian timing of the watches (Eriksen et al., 2006).

The fact that in both fixed schedules watchkeepers usually have two sleeps daily between watches could give rise to some circadian disorders. This might adversely affect the performance capacity of watchkeepers (Plett et al., 1988). In order to reduce this effect, there have been studies with alternative proposals to the traditional four-on/eight-off watchkeeping system, but the findings have not been conclusive (Fletcher et al., 1988).

Some investigations have shown that people engaged in a fixed 4/8 system achieve a better adaptation in quality of sleep than those engaged in other fixed or rotating systems. Taking sequential measurements of melatonin indicators from watchkeepers engaged in a fixed $4 / 8$ schedule as an index of their circadian rhythm timing, a study has reflected acceptable levels of adaptation to performing their tasks during the watches. Even though differences between the shifts were found, this experiment concluded that health and safety could be best served by operating the ship on a fixed 4/8 schedule (Arendt et al., 2006).

Weighing up the results of the investigations, it can be assumed that the most acute disruptive effects on a four-on/eight-off system are not those due to the shifts, but to the combination of shift work with overtime and sleep deprivation. This situation usually happens in commercial shipping because the full operational cycle of the vessels covers more tasks than those related to navigational watches. Undertaken pilotage, compulsory drills, mooring and un-mooring duties, meeting port authorities and cargo surveyors, and loading and discharge operations are, among others, tasks that must be assumed by watchkeepers and lookouts regardless of their previous sleep/wake schedule. This overtime work and 
sleep deprivation, especially when it precedes early morning watches, creates a potential safety risk in the watchkeepers' performance while they are carrying out navigation duties (van Leeuwen et al., 2013).

For the purpose of this paper, it is assumed that bridge officers and lookouts engaged in a four-on/eightoff system can develop an appropriate adaptation. This can be achieved if they have adequate sleep, do not abuse alcohol or drugs and if they are not forced to perform excessive overtime work between watches. Otherwise, watchkeepers will have a worse psychomotor vigilance performance, which will be reduced in very dim light conditions (night watches). Consequently, they will not be able to maintain the same level of alertness on night shifts as they do on daylight watches.

\section{Analysis of the influence of circadian disorders on shipping accidents}

In order to analyse the influence of solar light on the behaviour of the crew engaged in bridge watchkeeping, the abovementioned hypothesis is assumed: that navigation watchkeepers on a four-on/eight-off fixed schedule can maintain a level of alertness during their night shifts similar to that of their day shifts, provided that they develop a good adaptation to the night shifts. On the contrary, if the conditions for maintaining an acceptable shift adaptation are not met, the level of efficiency of watchkeepers will decrease. This dip in effectiveness will be more acute during the night; as a result, the probability of accidents will be higher at this time. Thereby, navigation incidents should reflect a higher frequency and a tendency to be more serious during night-time.

To test this hypothesis, a sample of collisions has been compiled with data obtained from the International Maritime Organisation (IMO) (IMO GISIS, 2020). The local time and the level of severity of each collision have been recorded. In the context of the present work, local time or ship time becomes an essential variable for the analysis. This is due to the fact that it is an indicator that reflects whether a particular ship was involved in an accident during daylight or at night. It should be noted that it is a common practice to adjust on-board clocks to changes in longitude on commercial vessels so that nonshift workers can perform their tasks in daylight. It is also a standard practice to match the ship time with the official time of the country in whose waters the ship is operating. These practices turn both the time of the ship and the official time of the country where the ship is operating into reliable indicators of the light/dark state of the solar day in any geographical position.

The duration of sunlight in a given location depends on latitude and solar declination. These factors alter the hours of sunset and sunrise. In order to stablish a specific period of darkness in any geographical place and on any day of the year, the ship's position is registered when the accident occurs. It has been observed that for all latitudes recorded, the sunset during the year occurs between $16.00 \mathrm{~h}$ and $22.00 \mathrm{~h}$ locally, and sunrise occurs between $05.00 \mathrm{~h}$ and 10.00 h depending on the hemisphere and the season. For the purpose of the present analysis, it is assumed that in a four-on/eight-off schedule, darkness always prevails in the 00-04 shift, and in the shifts 20 to 24 and 04 to 08 it is night most of the time. For the sake of statistical analysis, the division of periods of the day has been made to coincide with the shifts of the four-on/eight-off schedule. A ship operating with another system does not influence the present work, since the variable that defines the light/dark state is the time of day when the accident occurred.

This work focuses only on collisions because, in this type of incident, the time that elapses between the action/inaction of people in charge of navigation and that of the accident (collision) is very short. In other types of accidents, the time between the erratic performance and the accident can be up to several hours, for instance, many accident investigations related to groundings reflect that the stranding happened some hours after wrong decisions had been taken. In these cases, the relationship between the time of the accident and the level of sunlight exposure of those engaged in navigation tasks could reflect a wrong correlation.

The collisions used in the analysis have been taken from the IMO database. They have occurred during the last few decades, however, not all incidents in the database have been used, due to the fact that numerous erroneous data have been observed concerning the time of the accidents. The time at which each collision occurred has been checked against other sources and when no reliable source has been found the incident has been discarded. The sample finally used in this analysis consists of 1,163 


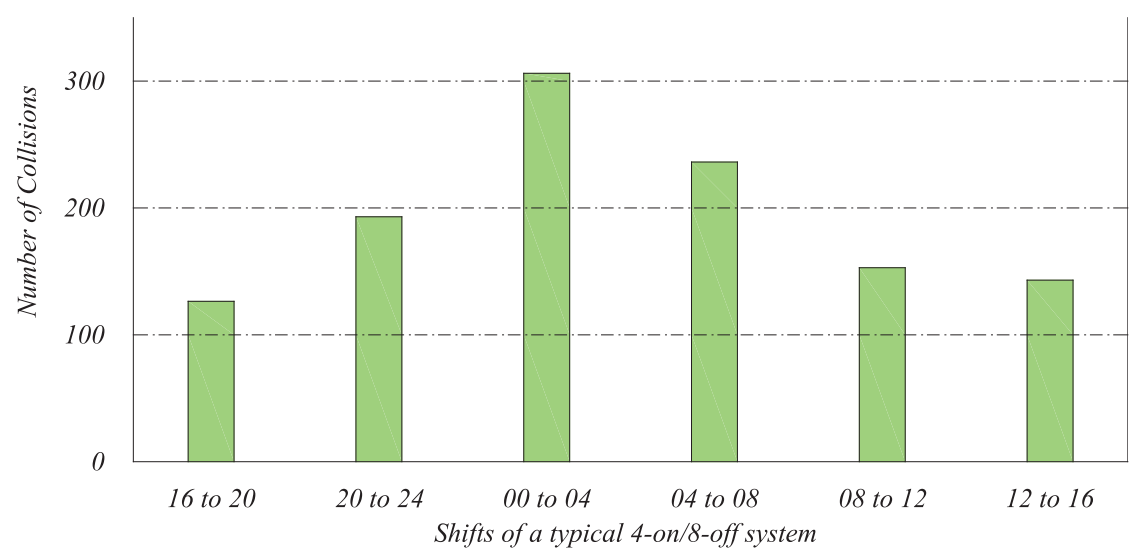

Figure 2. Number of collisions in different periods of the solar day that matches the shifts of a fouron/eight-off schedule $(h)$.

Table 1. Frequencies of expected and observed collisions in each sea-watch.

\begin{tabular}{lccr}
\hline Sea-watch (h) & Observed no. & Expected no. & Residual \\
\hline Middle (00-04) & 307 & $193 \cdot 8$ & $113 \cdot 2$ \\
Morning (04-08) & 237 & $193 \cdot 8$ & $43 \cdot 2$ \\
Forenoon (08-12) & 154 & $193 \cdot 8$ & $-39 \cdot 8$ \\
Afternoon (12-16) & 144 & $193 \cdot 8$ & $-49 \cdot 8$ \\
Dog (16-20) & 127 & $193 \cdot 8$ & $-66 \cdot 8$ \\
First (20-24) & 194 & $193 \cdot 8$ & $0 \cdot 2$ \\
Total & 1163 & & \\
\hline
\end{tabular}

collisions, involving 2,345 vessels worldwide. All the statistical calculations have been made with the program PASW Statistics 18.

It should be noted that in a system of fixed shifts such as four-on/eight-off, the watchkeeper and the lookout during a night shift have also been on duty hours earlier on a day shift, except in cases of crew changes. But these changes are usually made when the ship is in port. It is a relevant consideration whether, if there is an alteration in the safety level of a ship between day and night, the change is caused by the different behaviour of the same people. Thus, the result of the present analysis will reflect the difference in performance during the day and the night of a particular watchkeeper or lookout.

\subsection{The relationship between darkness and shipping accidents}

From the abovementioned sample of collisions, Figure 2 is prepared, which shows the number of this type of accidents in each period that matches the shifts of a typical four-on/eight-off system. It can be observed that the frequency of incidents differs depending on the watches. The objective of this analysis is to decide whether these differences among the shifts occur randomly or if there is a trend that makes the number of accidents increase in some periods of the solar day.

If we assume the null hypothesis that sunlight does not influence the behaviour of watchkeepers, the frequencies of collisions in the different periods of the day should be similar. In order to test this hypothesis, from the data a table is prepared, showing the expected and the observed collisions in each watch (Table 1).

Examination of the residuals shows that the number of collisions during night-time duty periods (middle and morning) is higher than expected, conversely, during daylight shifts (forenoon, afternoon 
Table 2. Output of chi-square test with significance.

\begin{tabular}{lc}
\hline & Sea-watch \\
\hline Chi square & $119 \cdot 726$ \\
Df & 5 \\
Asymp. sig. & $0 \cdot 000$ \\
\hline
\end{tabular}

Table 3. Cross-tabulation of type of accident on each sea-watch.

\begin{tabular}{lcccc}
\hline & \multicolumn{4}{c}{ Type of accident } \\
\cline { 2 - 5 } Sea-watch (h) & Less serious & Serious & Very serious & Active margin \\
\hline Middle 00-04 & 33 & 133 & 141 & 307 \\
Morning 04-08 & 38 & 103 & 96 & 237 \\
Forenoon 08-12 & 26 & 81 & 47 & 154 \\
Afternoon 12-16 & 24 & 65 & 55 & 144 \\
Dog 16-20 & 22 & 60 & 45 & 127 \\
First 20-24 & 27 & 75 & 92 & 194 \\
Active margin & 170 & 517 & 476 & 1163 \\
\hline
\end{tabular}

Table 4. Correspondence analysis showing value of the chi-squared statistic, its significance and dimensions.

\begin{tabular}{|c|c|c|c|c|c|c|c|c|}
\hline \multirow[b]{3}{*}{ Dimension } & \multirow{3}{*}{$\begin{array}{l}\text { Singular } \\
\text { value }\end{array}$} & \multirow[b]{3}{*}{ Inertia } & \multirow{3}{*}{$\begin{array}{c}\text { Chi } \\
\text { square }\end{array}$} & \multirow[b]{3}{*}{ Sig. } & \multicolumn{2}{|c|}{$\begin{array}{l}\text { Proportion } \\
\text { of inertia }\end{array}$} & \multicolumn{2}{|c|}{$\begin{array}{l}\text { Confidence } \\
\text { singular } \\
\text { value }\end{array}$} \\
\hline & & & & & Accounted & & Standard & Correlation \\
\hline & & & & & for & Cumulative & deviation & 2 \\
\hline Dimension 1 & $0 \cdot 117$ & $0 \cdot 014$ & & & 0.867 & 0.867 & 0.029 & $-0 \cdot 047$ \\
\hline Dimension 2 & $0 \cdot 046$ & $0 \cdot 002$ & & & $0 \cdot 133$ & $1 \cdot 000$ & 0.028 & \\
\hline Total & & $0 \cdot 016$ & $18 \cdot 426$ & $0 \cdot 048$ & 1.000 & $1 \cdot 000$ & & \\
\hline
\end{tabular}

and dog watches) the number of accidents is lower than expected. To determine if these differences among the shifts are statistically significant, a chi-square test is performed (Table 2).

The small significance value (less than 0.05) obtained indicates that the number of collisions during the night shifts, especially in the middle and morning watches, is significantly higher than in the daylight shifts. This result leads to the rejection of the null hypothesis. In other words, the differences in frequencies in the different watches cannot be explained by mere chance; therefore, it must be assumed that in night shifts the probability of collisions is higher. According to this result, it must be understood that the level of alertness of people on charge of bridge navigation watches becomes significantly lower during their night shifts. This is coherent with other regional investigations (MAIB, 2004. p. 10). 


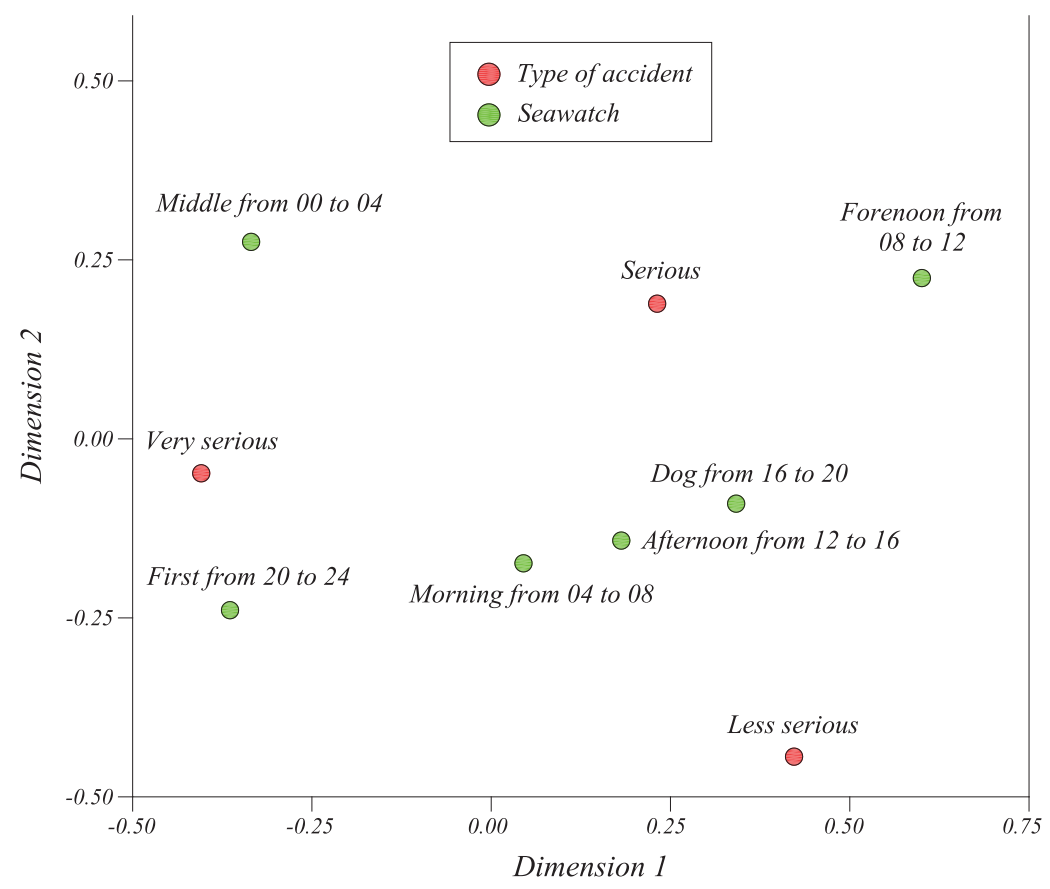

Figure 3. Bi-plot of the correspondence analysis between the type of accident and the type of watch, obtained with the program PASW Statistics 18.

\subsection{The influence of darkness on the seriousness of shipping accidents}

The above results indicate that watchkeepers and lookouts of the world commercial fleet tend to make mistakes more frequently at night. Another safety aspect then relates to the accuracy of their response to an incident. If it is accepted that the ability of people engaged in bridge navigation tasks is acutely reduced during the darkness period of the solar day, then a clumsier effectiveness in responding to the incident should also be expected. In these circumstances, the likelihood of more extensive damage will increase.

With the aim of analysing if there is any kind of relationship between the severity of the collisions and the lighting conditions of the shifts, the grade of severity of each incident in the sample of 1,163 collisions was recorded. This variable is directly obtained from the GISIS database, in which each accident is classified as very serious, serious or less serious, following the criteria established by IMO (MSC-MEPC.3-Circ.3. p. 2).

A cross-tabulation is prepared of the row variable (type of accident) by the column variable (sea-watch). The number of collisions that occurred in each period of time that matches the four-on/eight-off system is shown in each cell classified by the level of severity of each incident (Table 3).

The hypothesis that the different number of collisions represented in each cell happens by chance means that the light/darkness conditions of the different watches do not influence the behaviour of people on duty and, therefore, the severity of the collisions. In order to test this assumption, the statistical method of the correspondence analysis is applied. The results are shown in Table 4.

The summary Table 4 shows whether or not there is a relationship between the row and column variables, and the number of dimensions that are necessary to display the association graphically. The results show that two dimensions account for all the inertia in the solution. The chi-square statistic obtained allows us to test the null hypothesis that there is no relationship between the severity of the accidents and the light/darkness conditions of the different watches.

As the significance of the chi-square statistic is small (less than 0.05), the null hypothesis is rejected. Consequently, we can safely state that there is a significant relationship between the severity of the 
accidents and the light/darkness conditions of the different watches. In order to know the direction of this relationship, we obtain a two-dimensional graphical representation (Figure 3). In Figure 3, it can be seen that similar or related categories are close to each other in the plot. Thereby, it is easy to know, first, which categories of the same variable are similar and, second, which categories of the two variables are related between them. In the first case, it can be seen that afternoon, dog and forenoon watches (daylight shifts) are grouped on the right side of the graph. On the contrary, night shifts appear on the left. These groupings clearly indicate the underlying feature of the dark/light periods of the solar day.

We can also see the relationship between the categories of the two variables in terms of distance. Thus, although in the category of serious accidents there is no clear relationship with the different shifts, those accidents clasified as very serious are closely related to darkness watches (middle, first and morning) and less serious accidents are closely related to daylight watches (afternoon and dog).

The results obtained with the correspondence analysis show that accidents at sea tend to be more serious during night-time than during the daylight watches. This is explained by the fact that darkness or very dim light in the navigation bridge significantly reduces the ability of watchkeepers and lookouts to carry out their tasks.

\section{Conclusions}

The reduction of manning levels in vessels to save costs has become a current policy in the shipping business, made possible by the implementation of safety improvements and automation. In this risk compensation process, shipping business decision-makers take advantage of technological developments to introduce more profitable but riskier alternative maritime operations.

Excessive working hours and fatigue on board have become widely recognised issues. This has been confirmed by many accident investigations which reflect that the low alertness of bridge watchkeepers and lookouts is the cause of fatal navigational errors. This lead the authors to investigate whether the behaviour and skills of the people in charge of the navigation bridge are different in their daytime and night-time shifts. The presumption of this difference in ability arises from the belief that people in charge of navigation, if they are affected by circadian disorders and are not properly assisted by lookouts, will have a markedly lower level of alertness during their night shifts. This difference in ability is due to the fact that night work on navigation bridges must be carried out in darkness or very dim light, circumstances that reduce the level of alertness of watchkeepers. Although there are numerous factors, different from the biological ones, that influence a particular accident (i.e., crew training, crew experience, size of vessels, sea state, visibility, density of ships in the zone, accurate charts, etc.), none of them can explain why incidents happen more frequently at night.

The result of the analysis confirms that collisions between vessels are more frequent at night and that these accidents are usually more serious than during the daylight watches. This does not mean that bridge officers and lookouts are not affected by fatigue during sunlight shifts, but that the necessary absence of light to improve the vision during the night watches diminishes their skills. As a result, the probability of shipping accidents fluctuates according to a circadian rhythm with peaks during the night. Although this analysis has focused only on collisions, it should be accepted that it affects any kind of task carried out by watchkeepers, which means that the results obtained in this investigation can be extrapolated to any type of navigation incidents.

Competing interest. None.

\section{References}

Anderson, M. (2013). Contemporary Ergonomics and Human Factors. London: Taylor \& Francis. doi:10.1201/b13826.

Arendt, J. (1995). Melatonin and the Mammalian Pineal Gland. London: Chapman \& Hall.

Arendt, J., Middleton, B., Williams, P., Francis, G. and Luke, C. (2006). Sleep and circadian phase in a ship's crew. Journal of Biological Rhythms, 21(3), 214-221. doi:10.1177/0748730405285278.

Baniela, S. and Ríos, J. (2010). The risk homeostasis theory. The Journal of Navigation, 63(4), 607-626. doi:10.1017/S0373463310000196. 
Cajochen, C., Zeitzer, J. M., Czeisler, C. A. and Dijk, D. J. (2000). Dose-response relationship for light intensity and ocular and electroencephalographic correlates of human alertness. Behavioural Brain Research, 115(1), 75-83. doi:10.1016/s01664328(00)00236-9.

Calhoun, S. R. (1999). Human Factors in Ship Design: Preventing and Reducing Shipboard Operator Fatigue. University of Michigan/U.S. Coast Guard Research Project. https://pdfs.semanticscholar.org/7812/ a76b183e76a4fccf6855272b4b93de553f22.pdf (accessed 12 December 2019).

Cappuccio, F. P., Miller, M. A., Lockley, S. W. and Rajaratnam, S. M. W. (2018). Sleep, Health, and Society: From Aetiology to Public Health. Oxford University Press. doi:10.1093/oso/9780198778240.001.0001

Condon, R., Colquhoun, W. P., Knauth, P., Plett, R., Neidhart, B., DeVol, D., Eickhoff, S. and Rutenfranz, J. (1988). Work at sea: A study of sleep, and of circadian rhythms in physiological and psychological functions, in watchkeepers on merchant vessels. V. Effects of time zone crossings. International Archives of Occupational and Environmental Health, 61, 39-49. doi:10.1007/BF00381606.

Daurat, A., Aguirre, A., Foret, J., Gonnet, P., Keromes, A. and Benoit, O. (1993). Bright light affects alertness and performance rhythms during a 24-h constant routine. Physiology \& Behavior, 53(5), 929-936. doi:10.1016/0031-9384(93)90271-g.

Dawson, D. and Campbell, S. S. (1991). Timed exposure to bright light improves sleep and alertness during simulated night shifts. Sleep: Journal of Sleep Research \& Sleep Medicine, 14(6), 511-516. doi:10.1093/sleep/14.6.511.

Dickie, J. W. (2014). Reeds 21 st Century Ship Management. London: Edlard Coles Nautical.

Eriksen, C. A., Gillberg, M. and Vestergren, P. (2006). Sleepiness and sleep in a simulated 'six hours on/six hours off' sea watch system. Chronobiology International, 23(6), 1193-1202. doi:10.1080/07420520601057981.

Fletcher, N., Colquhoun, W. P., Knauth, P., DeVoll, D. and Plett, R. (1988). Work at sea: A study of sleep, and of circadian rhythms in physiological and psychological functions, in watchkeepers on merchant vessels. VI. A sea trial of an alternative watchkeeping system for the merchant marine. International Archives of Occupational and Environmental Health, 61, 51-57. doi:10.1007/BF00381607.

Folkard, S., Lombardi, D. A. and Spencer, M. B. (2006). Estimating the circadian rhythm in the risk of occupational injuries and accidents. Chronobiology International, 23(6), 1181-1192. doi:10.1080/07420520601096443.

Härmä, M., Partinen, M., Repo, R., Sorsa, M. and Siivonen, P. (2008). Effects of 6/6 and 4/8 watch systems on sleepiness among bridge officers. Chronobiology International, 25(2-3), 413-423. doi:10.1080/07420520802106769.

Horowitz, T. S., Cade, B. E., Wolfe, J. M. and Czeisler, C. A. (2001). Efficacy of bright light and sleep/darkness scheduling in alleviating circadian maladaptation to night work. American Journal of Physiology Endocrinology and Metabolism, 281(2), E384-E391. doi:10.1152/ajpendo.2001.281.2.E384.

IMO GISIS (2020). IMO Global Integrated Shipping Information System: Marine Casualties and Incidents. International Maritime Organisation. Available at: https://gisis.imo.org/Public/MCI/Default.aspx (accessed 8 March 2020).

Iskra-Golec, I., Barnes-Farrell, J. and Bohle, P. (2016). Social and Family Issues in Shift Work and Non Standard Working Hours. Switzerland: Springer. doi:10.1007/978-3-319-42286-2.

Kelly, H. and Adamopoulos, A. (2017). Sleepy on the high seas. Lloyd's List. 31 January. https://lloydslist.maritimeintelligence. informa.com/LL110288/Sleepy-on-the-high-seas (accessed 14 March 2021).

Klein, D. C., Moore, R. Y. and Reppert, S. M. (1990). Suprachiasmatic Nucleus: The Minds Clock. New York: Oxford University Press.

Kumar, V. (2017). Biological Timekeeping: Clocks, Rhythms and Behaviour. Delhi: Springer. doi:10.1007/978-81-322-3688-7.

Lloyd's List. (2012). Asleep at the wheel. Analysis. Lloyd's List. 1 February. https://lloydslist.maritimeintelligence.informa.com/ LL030021/Asleep-at-the-wheel (accessed 14 March 2021).

MAIB (2004). Bridge Watchkeeping Safety Study 1/2004. Marine Accident Investigation Branch. https://www.gov.uk/government/ publications/bridge-watchkeeping-safety-study (accessed 24 January 2020).

MSC-MEPC.3-Circ.3 (2008). Casualty-Related Matters: Reports on Marine Casualties and Incidents (Revised harmonized reporting procedures-Reports required under SOLAS regulation I/21 and MARPOL, articles 8 and 12), p. 2. http://www.imo. org/en/OurWork/MSAS/Casualties/Documents/MSC-MEPC.3-Circ.3.pdf. (accessed 5 February 2020).

OJ L 102 (2006). Regulation (EC) No 561/2006. Official Journal of the European Union, 49, 1-14. https://eur-lex.europa.eu/eli/ reg/2006/561/oj (accessed 3 February 2020).

OJ L 167 (1999). Council Directive 1999/63/EC. Official Journal of the European Union, 42, 33-37. http://data.europa.eu/eli/ dir/1999/63/oj (accessed 3 February 2020).

Paul, M. A., Hursh, S. R. and Miller, J. C. (2010). Alternative Submarine Watch Systems: Recommendation for a New CF Submarine Watch Schedule. Defense R\&D Canada. Technical Report DRDC Toronto TR 2010-001. https://apps.dtic.mil/dtic/ tr/fulltext/u2/a517285.pdf (accessed 11 December 2019).

Plett, R., Colquhoun, W. P., Condon, R., Knauth, P., Rutenfranz, J. and Eickhoff, S. (1988). Work at sea: A study of sleep, and of circadian rhythms in physiological and psychological functions in watchkeepers on merchant vessels. III. Rhythms in physiological functions. International Archives of Occupational and Environmental Health, 60, 395-403. doi:10.1007/BF00381386.

Postnova, S., Robinson, P. A. and Postnov, D. D. (2013). Adaptation to shift work: physiologically based modeling of the effects of lighting and shifts' start time. PLoS One, 8(1), e53379. doi:10.1371/journal.pone.0053379.

Rana, S. and Mahmood, S. (2010). Circadian rhythm and its role in malignancy. Journal of Circadian Rhythms, 8, p. Art. 3. doi:10.1186/1740-3391-8-3. 
Russ, A. (2018). The human element - the effects of fatigue on ship safety. Part 1 - practical advice to shipowners. Standard Safety, July 2018, 6-8. https://www.standard-club.com/media/2767722/the-human-element-the-agffects-of-fatigue-on-shipsafety.pdf (accessed 21 January 2020).

Tozawa, T., Mishima, K., Satoh, K., Echizenya, M., Shimizu, T. and Hishikawa, Y. (2003). Stability of sleep timing against the melatonin secretion rhythm with advancing age: clinical implications. The Journal of Clinical Endocrinology \& Metabolism, 88(10), 4689-4695. doi:10.1210/jc.2003-030147.

van Leeuwen, W. M. A., Kircher, A., Dahlgren, A., Lützhöft, M., Barnett, M., Kecklund, G. and Åkerstedt, T. (2013). Sleep, sleepiness, and neurobehavioral performance while on watch in a simulated $4 \mathrm{~h}$ on $/ 8 \mathrm{~h}$ off marine watch system. Chronobiology International, 30(9), 1108-1115. doi:10.3109/07420528.2013.800874.

Vinagre-Ríos, J. and Iglesias-Baniela, S. (2013). The human element in shipping casualties as a process of risk homeostasis of the shipping business. The Journal of Navigation, 66(3), 385-397. doi:10.1017/S0373463313000064.

Wynn, T., Howarth, P. A. and Kunze, B. R. (2012). Night-time lookout duty: The role of ambient light levels and dark adaptation. The Journal of Navigation, 65(4), 589-602. doi:10.1017/S0373463312000288.

Yilmaz, H., Basar, E. and Yüksekyildiz, E. (2013). Investigation of Officer's Navigation and Port Watches Exposed to Excessive Working Hours. Marine Navigation and Safety of Sea Transportation: Advances in Marine Navigation. Boca Raton, FL: CRC Press. doi:10.1201/b14961. 